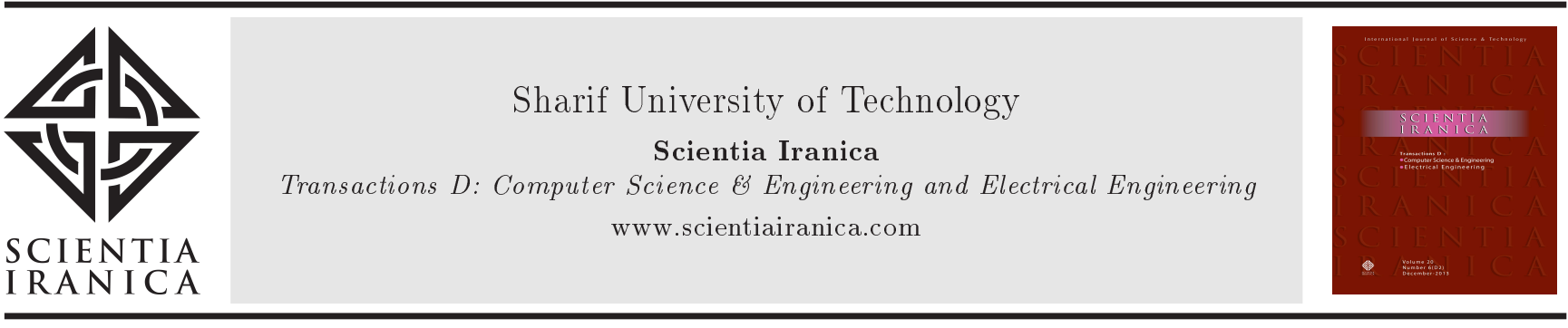

\title{
Spectral method for PEMFC operation mode monitoring based on electrical fluctuation analysis
}

\author{
E. Denisov ${ }^{\mathrm{a}, *}$, Yu.K. Evdokimov ${ }^{\mathrm{a}}$, R.R. Nigmatullin ${ }^{\mathrm{a}}$, S. Martemianov ${ }^{\mathrm{b}}$, \\ A. Thomas ${ }^{\mathrm{b}}$ and N. Adiutantov ${ }^{\mathrm{a}, \mathrm{b}}$ \\ a. Kazan National Research Technical University named after A.N. Tupolev-KAI, 10 K. Marx St., 420111, Kazan, Russian \\ Federation. \\ b. Institut Pprime, UPR 3346 CNRS, Université de Poitiers, ENSMA, Batiment B25:2, Rue Pierre Brousse - TSA 41105 - 86073 \\ POITIERS Cedex 9, France.
}

Received 2 December 2015; received in revised form 5 February 2016; accepted 10 May 2016

\section{KEYWORDS \\ Fuel cell; \\ Technical diagnostics; \\ Flicker noise; \\ Water management.}

\begin{abstract}
This work considers the possibility of applying electrochemical noise analysis to fuel cell diagnostics. Theoretical hypothesis and experimental result have shown that spectral characteristics of electrical fluctuations depend on water management processes inside the PEMFC. It has been established that the spectrum of electrical fluctuations in low frequency range has the nature of flicker noise. The frequency ranges of $0.1-1 \mathrm{~Hz}$ convenient for single cell as well as for stack diagnostics are revealed. The results show that the proposed approach can be considered as an effective tool to diagnose of fuel cells, namely allowing for prediction of drying and flooding.

(C) 2017 Sharif University of Technology. All rights reserved.
\end{abstract}

\section{Introduction}

There are many types of effective energy sources, but lately, scientists have been paying a great deal of attention to further researching the Polymer Exchange Membrane Fuel Cells (PEMFC) and Lithium-Ion (LiIon) batteries, which are the most promising energy sources for the near future. In the PEMFCs, hydrogen and oxygen are electrochemically combined to produce electrical energy without the essential interim step of heat production. It gives the PEMFC extremely high efficiency of up to 0.83 [1]. Reaction byproducts are water, and some waste heat is also used to produce additional power [2]. The PEMFC is considered an environmentally friendly source, since it does not produce greenhouse gas emissions.

Despite the mentioned advantages, the PEMFCs have insufficient operational characteristics, namely

\footnotetext{
*. Corresponding author. Tel.: +7843 2389375;

Fax: +78432366032

E-mail address: genia-denisov@yandex.ru (E. Denisov)
}

reliability and durability, which are strong barriers to their wide utilization. However, these problems can be solved by means of the PEMFC technical state diagnostics [3-6] adopted to detect and possibly predict failures at the initial stages and to try to neutralize the effects of failures to keep high operational characteristics. Development of corresponding methods and systems is an extremely difficult task since PEMFC operation is determined by several factors (pressure, reactant gases humidification, cell temperature, electrical operation mode, and others) and also considerably depends on the current technical state of membrane electrodes assembly and gas transport channels [1,7-9]. All these factors have a great deal of influence on energy conversion efficiency and operation stability. Therefore, in the current hydrogen energy industry on the basis of fuel cells, one of the problems is development of reliable diagnostic method of the fuel cell directly during its operation.

A lot has been written about dealing with diagnostic methods applied to fuel cells (see [3-5] and references therein), but the problem of developing 
applicable and reliable diagnostic tools without any operation interruption has not been fully resolved. For development of the corresponding diagnostic systems, information properties of the PEMFC electrical noise and fluctuations are suggested for use within the scope of this work.

The latest research [7-10] shows that electric fluctuations reflecting physical processes occurring in electrochemical objects can be used for diagnostic purposes. Compared to other traditional electrochemical methods (polarization curve, electrochemical impedance spectroscopy, etc.), Electrical Noise Analysis (ENA) has many advantages such as rapidity, high informativity, and non-intrusiveness (the absence of external signal for the collection of experimental data). In this condition, the diagnostic method based on informational properties of electrical fluctuation is promising, since it allows for developing diagnostic systems which do not require perturbation of the FC operation mode [7,9]. At present, fluctuation phenomena during long-term operation mode occurring in the fuel cell are not fully explored. This work is dedicated to the development of diagnostic tools based on spectral characteristics of electrical fluctuations. It will enable the process of evaluating the degree of degradation of the equipment that allows for control of remaining useful life by changing the FC settings.

One of the main problems in the field of developing PEMFC systems is providing correct water management [11-19]. Analysis of the publications shows that great effort is directed at the understanding and quantitative description of water management processes $[11,18,19]$ to identify influencing factors $[13,15,17]$ for selection of materials [12], optimization of construction of the PEMFC [14], and control of the water management process [16]. The present work is focused on the problem of monitoring water management condition based on fuel cell electrical fluctuation analysis.

\section{Spectral characteristics of electrical fluctuations of PEMFC}

\subsection{PEMFC electrical fluctuations}

Electrical fluctuations are inherent properties of any electrochemical system and can be used for direct characterization of its condition. Diagnostic methods based on electrochemical noises are widely used for studying metal films and electrode corrosion, quality of passivation coatings, charging level estimation, and overcharging detection for electrochemical batteries, etc. An essential advantage of the noise (fluctuation) method is absence of any perturbation of electrochemical system by external probing signals. Observing electrical fluctuations during PEMFC operation could be divided into two large groups: (1) electrical noises

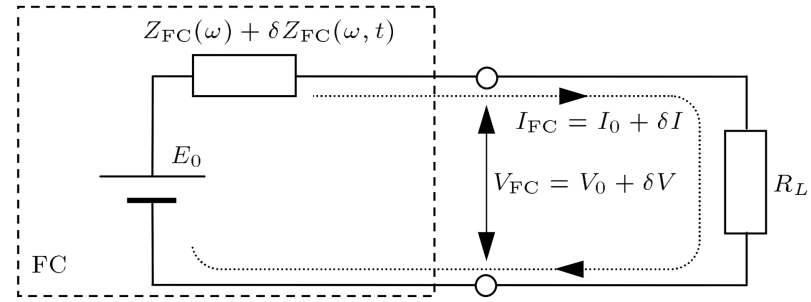

Figure 1. Origin of FC electrical current and voltage fluctuation.

(thermal, short, generation-recombination, and flicker noises), and (2) fluctuations caused by stochastic variation (instability) of electrical parameters of FC components. In this paper, we focus on the second group of fluctuations as they have a strong relationship with the PEMFC technical state and normally have large amplitudes making their measurement easier.

During the FC operation process, stochastic variations (fluctuations) of the FC components of physicochemical parameters are observed. Due to the inconsistency of Membrane Electrode Assembly (MEA) for humidification modes, fluctuations of temperature and gas pressure maintenance of polymer membrane resistance, electrochemical reaction rates, diffusions coefficients, and double electrical layer thickness arise. These fluctuations cause stochastic variations of intrinsic FC electrical impedance $\delta Z_{\mathrm{FC}}(\omega, t)$, and consequently provoke electrical current $\delta I$ and voltage $\delta V$ fluctuations (Figure 1).

Statistical parameters of such fluctuations should essentially depend on the current values of fuel cell physicochemical parameters and potentially have capacities which allow for realization of FC components' technical diagnostics. In other words, analysis of electrical current and voltage fluctuations can be considered as a basis for a reliable PEMFC diagnostic tool.

\subsection{PEMFC electrical fluctuations caused by water condensation and evaporation processes}

Within the scope of this work, the FC electrical fluctuations are understood as stochastic spontaneous variations of electrical current or voltage of FC. Such fluctuations take place even during operation under constant operational condition. The basic sources of the fluctuations are:

1. Instabilities in fuel and oxidized flows due to nonideal construction of flow rate control systems;

2. Surges within flows of gases due to eddies caused by joints, abruptness, etc. within gas transport channels;

3. Variation in stoichiometry;

4. Variation of effective surface and activity of catalyst; 
5. Water condensation and evaporation processes within gas transport channels and the MEA;

6. Condensed water drops blowing out and breaking by gas flows.

Each of these factors exerts influence on the FC electrical fluctuation spectrum. The effects of factors 1-3 could be significantly reduced by means of proper design of gas supply systems. The forth factor leads to long-term trends, reducing generating current. The influence of this factor could be significantly reduced by means of thorough cleaning of fuel and oxidizer.

Factor 6 is essential in case of large sizes of condensed drops and high gas flow rates [11]. During blowing off, a drop is "flattened" and the diameter of the drop increases in the contact area with the electrode surface:

$$
d_{d}=K^{\prime} c_{D} \operatorname{Re}^{2},
$$

where $c_{D}$ is drag coefficient, $K^{\prime}$ is dimension factor $(\mu \mathrm{m})$, Re is Reynolds number.

The additional possible source of electrical fluctuation observed during PEMFC operation is that of the condensation and evaporation processes in the region of Membrane Electrodes Assembly (MEA). These processes may provide drop formation on the membrane and electrodes which block reactants' delivery into the zone of electrochemical reaction. If we suppose that a water drop has a typical length scale (diameter, $d$ ), then the following area of a membrane surface is blocked:

$$
S_{b}=\pi \times d^{2} / 4 .
$$

The time variation of the blocked area leads to alteration of value of the produced current:

$$
\delta I_{\mathrm{FC}}(t)=k \times S_{b}(t) .
$$

Here, $k$ is proportionality factor.

As shown in [11] on the basis of empirical dependencies, growth of drop diameter during condensation within the MEA of the PEMFC could be described by the following equation:

$$
D(t)=0.62 \times t^{0.1} .
$$

Here, $t$ is time in seconds, and $D$ is diameter of the drop in millimeters. The measurements have been carried out in 40 seconds under flow velocity $4,25 \mathrm{~m} / \mathrm{s}$. At the moment $t=1 \mathrm{~s}$, the drop diameter was $0.62 \mathrm{~mm}$ [11]. Using dependences in Eqs. (3) and (4), it can be shown that such a growth of drop corresponds to the current variation:

$$
\delta I_{\mathrm{FC}}(t)=0.0961 \times k \times \pi \times t^{0.1} .
$$

We can suppose that in general, current variations caused by condensation can be described by the following formula:

$$
\delta I_{\mathrm{FC}}(t)=a \times t^{\alpha},
$$

where $a$ is dimension proportionality factor, and $\alpha$ is a fractional factor.

Under the actual operating conditions, condensation and evaporation take place simultaneously within the MEA. The results of the reciprocal action of the two processes lead to drop diameter changes described by the equation:

$$
D(t)=a_{0} \times t^{\Delta \psi}=a_{0} \times t^{(\alpha-\beta)},
$$

where $\Delta \psi=(\alpha-\beta) ; \alpha$ and $\beta$ are parameters corresponding to condensation and evaporation, respectively. Variation of drops diameters changes the blocked area of MEA's active layer:

$$
S_{b}(t)=\pi \times a_{0}^{2} / 4\left(t^{2 \Delta \psi}\right) .
$$

It leads to changing of the current according to Eq. (3):

$$
\delta I_{\mathrm{FC}}(t) \sim k \frac{\pi a_{0}^{2}}{4} t^{2 \Delta \psi}
$$

Due to the presence within the MEA and gas transport channels, a great number of drops of different sizes (the greater part of which normally has small sizes) of condensation and evaporation cause complex fluctuation of effective membrane surface and corresponding electrical fluctuations. With standard tables of integral transform at hand [20], spectral representation of the current fluctuation can be expressed by the following equation:

$$
\delta F_{I_{\mathrm{FC}}}(j \omega)=A_{0} \frac{\Gamma(1+2 \Delta \psi)}{(j \omega)^{1+2 \Delta \psi}}
$$

where $\Gamma$ is Gamma function, $A_{0}$ is proportionality coefficient, and $\Delta \psi=\alpha-\beta$.

Therefore, the Power Spectrum Density (PSD) of the electrical fluctuations corresponding to condensation-evaporation processes is expressed as:

$$
S_{I}(\omega) \sim\left|\delta F_{I_{\mathrm{FC}}}(j \omega)\right|^{2}=A_{0}^{2} \frac{\Gamma^{2}(1+2 \Delta \psi)}{(j \omega)^{2+4 \Delta \psi}} .
$$

Analysis of Eq. (11) shows that these fluctuations correspond to the flicker noise nature:

$$
S(f) \sim \frac{1}{f^{\gamma}}, f \leq 1 \mathrm{~Hz}
$$

where $\gamma=2+4 \Delta \psi$.

These results show that electrical fluctuations contain information about the quality of water management inside the MEA, and therefore reflect the PEMFC technical state. Thus, electrical fluctuation can be considered as the basis for PEMFC diagnostic system whose diagnostic features will be analyzed in the experimental part of this work. 


\section{Experimental study of PEMFC electrical fluctuation}

\subsection{Experimental setup for PEM fuel cell fluctuation characteristics measurement}

An automated measurement system for investigating fuel cell electrical fluctuation or the Fuel Cell Test Station (FCTS) has been developed for fluctuation measurement (Figure 2). This system consists of two parts: Fuel cell operability assurance subsystem and Electrical noise (fluctuation) measurement system. The BANC TEST installation produced by Fuel cell technologies Inc. was used for PEMFC operability assurance. This installation allows for choosing a type of oxidizer (oxygen or air) and control of seven fuel cell operation parameters: temperature of $\mathrm{FC}\left(T_{\mathrm{FC}}\right)$, humidity of fuel $\eta_{a}$, and oxidizer $\eta_{c}$ gases, anode $Q_{a}$ and cathode $Q_{c}$ flow rates, anode $P_{a}$ and cathode $P_{c}$ backpressures.

The fuel cell operability assurance subsystem works in the following manner. Flow rate controllers (FRC1, FRC2) provide fuel cell anode and cathode with hydrogen and oxygen. Reactant gases can go directly to fuel cell inlets through the anode (AHS) and cathode (CHS) humidification systems in dependence on anode (AMS) and cathode (CMS) humidification mode of selector positions. Humidity of fuel, $\eta_{a}$, and oxidizer, $\eta_{c}$, is controlled by temperatures of anode $T_{t H A}$ and cathode $T_{\mathrm{HC}}$ humidification systems, respectively. The backpressure controllers are placed after the fuel cell anode (ABPC) and cathode (CBPC) outlets. Cell temperature is set by the Temperature Controller (TC).

Temperature controllers of cell and both humidifiers are based on CN76122 T/C controllers with the accuracy of $\pm 0.25^{\circ} \mathrm{C}$. Backpressure controllers have accuracy better than $2 \%$. FCTS experimental setup operates under the control of computerized system of controls and measurements. Software has been created in the program environment LabVIEW 8.5 of National
Instruments. The computerized system is connected to the anode (AFRC) and cathode (CFRC) flow rates controllers, allowing for maintaining flow rates with inaccuracy of less than $1 \%$ of the rated value.

The Impedance Measuring System (IMS) is based on the built-in BANC TEST installation impedance meter. The IMS allows for measuring FC impedance characteristics at the frequency range of $0.01 \mathrm{~Hz}$ $40 \mathrm{~Hz}$ with relative error of real and imaginary part measurements lower than 0.25\%. Electric Signal Measuring system (ESM) has been developed to measure FC electrical and fluctuation signals. A block diagram of this system is shown in Figure 2.

The fuel cell electric signal measuring system has two measuring channels. The developed two-channel measuring is based on data acquisition board NI PXI5922 (National Instruments Inc.), and low-noise amplifier is made on the basis of the INA 103 microcircuit (Burr Brown Inc.), which has sensitivity better than $1.5 \mathrm{nV} / \mathrm{Hz}^{0.5}$ ). NI PXI-5922 has a resolution of 24 bits at sampling rates of up to $50 \mathrm{kHz}$ and the root-meansquare noise voltage $<1 \mu \mathrm{V}$ (Figure 3 ).

A two-channel noise measuring system provides measurement of complete $\mathrm{FC}$ voltage signal by the first channel:

$$
V_{\mathrm{FC}}=V_{0}+u(t) \text {. }
$$

Here, $V_{0}=\overline{V_{\mathrm{FC}}}$ is $\mathrm{DC}$ component of FC voltage, $u(t)$ is fluctuation component of FC voltage, and only fluctuation component $u(t)$ of full signal in the frequency

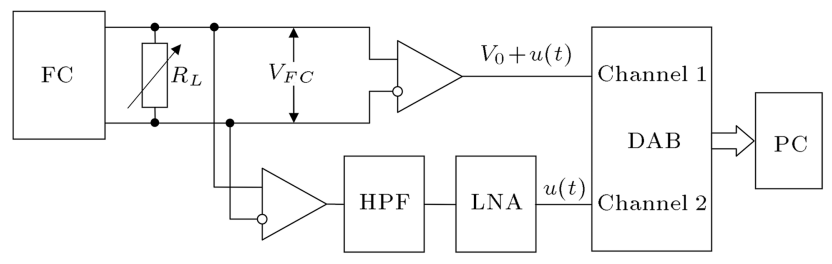

Figure 3. Block diagram of fuel cell electric signal measuring system.

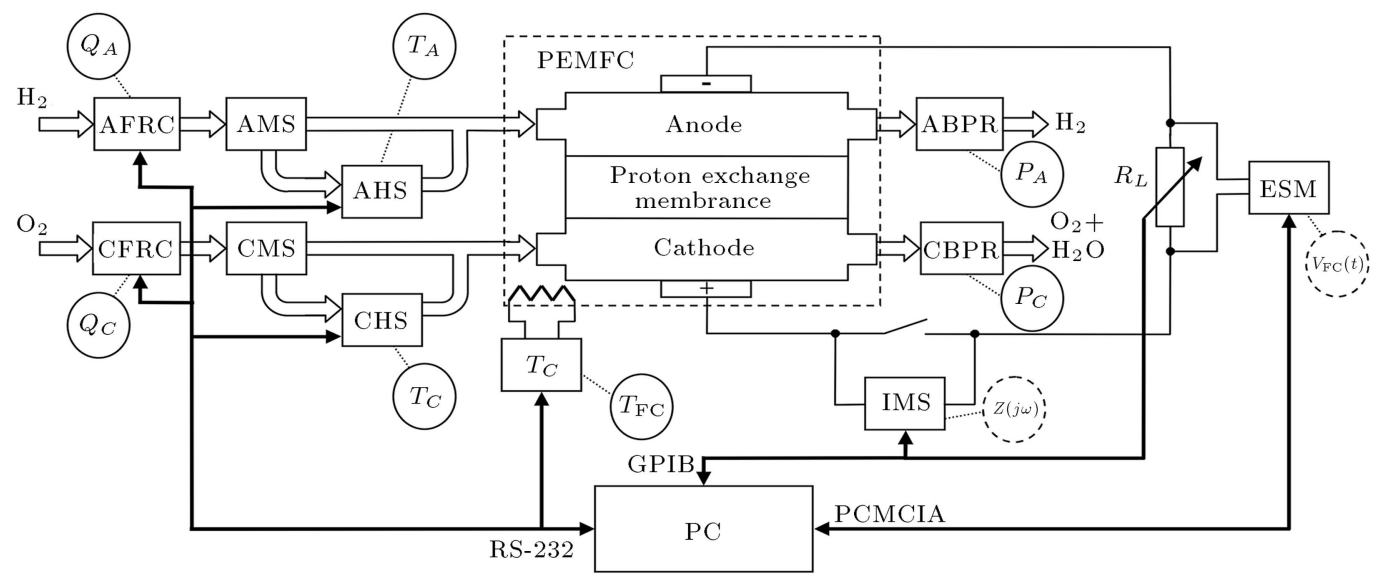

Figure 2. Block diagram of fuel cell testing system. 
Table 1. Measurement information of system for single PEMFC analysis.

\begin{tabular}{cccccccc}
\hline No. & Measured quantity & Notation & Unit & \multicolumn{2}{c}{ Type of quantity } & Range & Accuracy \\
\cline { 5 - 7 } & & & & Controlled Measured & \\
\hline 1 & FC temperature & $T_{\mathrm{FC}}$ & ${ }^{\circ} \mathrm{C}$ & + & + & $0-100$ & $\pm 0.25^{\circ} \mathrm{C}$ \\
2 & Temperature of anode humidification system & $T_{\mathrm{HA}}$ & ${ }^{\circ} \mathrm{C}$ & + & + & $0-100$ & $\pm 0.25^{\circ} \mathrm{C}$ \\
3 & Temperature of cathode humidification system & $T_{\mathrm{HC}}$ & ${ }^{\circ} \mathrm{C}$ & + & + & $0-100$ & $\pm 0.25^{\circ} \mathrm{C}$ \\
4 & Flow rate of anode gas & $Q_{A}$ & $\mathrm{ml} / \mathrm{min}$ & + & + & $0-1000$ & $1 \%$ \\
5 & Flow rate of cathode gas & $Q_{C}$ & $\mathrm{ml} / \mathrm{min}$ & + & + & $0-2000$ & $1 \%$ \\
6 & Anode backpressure & $P_{A}$ & $\mathrm{kPa}$ & + & + & 400 & $2 \%$ \\
7 & Cathode backpressure & $P_{C}$ & $\mathrm{kPa}$ & + & + & 600 & $2 \%$ \\
8 & Load resistance & $R_{L}$ & $\mathrm{Ohm}$ & + & + & $0.01-1000$ & $0.1 \%$ \\
8 & FC impedance & $Z(j \omega)$ & $\mathrm{Ohm}$ & + & - & $0-1000$ & $0.25 \%$ \\
9 & FC voltage & $V_{\mathrm{FC}}$ & $\mathrm{V}$ & + & - & $0-5$ & $0.6 \mu \mathrm{V}$ \\
\hline
\end{tabular}

range $1 \mathrm{~Hz}-2 \mathrm{k} \mathrm{Hz}$ by the second channel. A signal processing program has been also written in the program environment LabVIEW 8.5. Thus, the developed Fuel Cell Testing System allows for measuring 9 quantities describing fuel cell operation mode. Measurements of values, their notations, units of measurement, range, and accuracy are presented in Table 1.

\subsection{Electrical fluctuation of a single PEMFC}

The results presented in this section are obtained for a single PEMFC of the P'prime laboratory of the University of Poitiers (France). The Membrane Electrodes Assembly (MEA) of the considered fuel cell has been produced under the hot pressing method $\left(T=120^{\circ} \mathrm{C}, P=7,8 \mathrm{MPa}, t=130 \mathrm{~s}\right)$. Catalytic layers placed on the proton exchange membrane Nafion 117 contained $40 \%$ of mass fraction of $\mathrm{Pt}$ on carbon carrier unit Vulcan XC-72 with $0.5 \mathrm{mg} / \mathrm{cm}^{2}$ platinum loading and $20 \%$ mass fraction of teflon PTFE. A hydrophobic carbon cloth has been used as the backing layer. Active surface area of square electrodes was equal to $5 \mathrm{~cm}^{2}$. The MEA has been placed between two bipolar plates with gas transport channels having a single-channel serpentine configuration. The width and depth of the gas transport channels is $1 \mathrm{~mm}$. The width of the copper current collector plate is also $1 \mathrm{~mm}$.

An example of Power Spectral Density (PSD) $S^{\prime \prime}(f)$ of PEMFC fluctuation reduced to square average voltage ${\overline{V_{\mathrm{FC}}}}^{2}$ is measured for the operation mode corresponding to the following parameters:

$$
\begin{aligned}
& T_{\mathrm{FC}}=60^{\circ} \mathrm{C}, \quad T_{\mathrm{HA}}=50^{\circ} \mathrm{C}, \\
& T_{\mathrm{HC}}=\text { dry (without humidification), } \\
& Q_{A}=600 \mathrm{ml} / \mathrm{min}, \quad Q_{c}=600 \mathrm{ml} / \mathrm{min}, \\
& P_{A}=P_{C}=300 \mathrm{kPa},
\end{aligned}
$$

which are presented in Figure 4.

The reduced PSD $S^{\prime \prime}(f)$ has been measured in the frequency range of $0.1-100 \mathrm{~Hz}$. The lower frequency

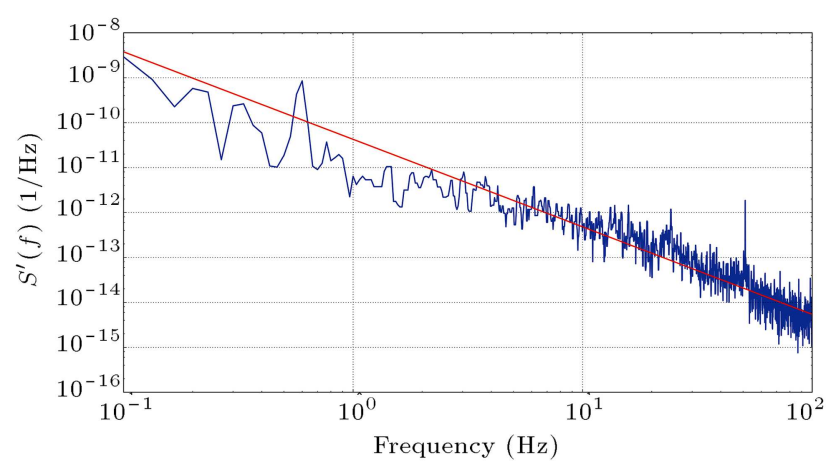

Figure 4. Typical power spectral density $S^{\prime}(f)$ reduced to $\mathrm{FC}$ square of average voltage $\overline{V_{\mathrm{FC}}^{2}(t)}$ of PEMFC fluctuations measured in operation mode: $T_{\mathrm{FC}}=60^{\circ} \mathrm{C}$; $T_{\mathrm{HA}}=50^{\circ} \mathrm{C} ; T_{\mathrm{HC}}=\operatorname{dry}($ without humidification $) ;$ $Q_{A}=600 \mathrm{ml} / \mathrm{min} ; Q_{C}=600 \mathrm{ml} / \mathrm{min}$; $P_{A}=P_{C}=300 \mathrm{kPa}$.

range limit has been chosen in order to enhance fluctuation from slow variations of generated electrical current (voltage) by frequency filtering. The upper frequency range limit $(100 \mathrm{~Hz})$ has been selected under the condition of a reliable measuring information, which obtains:

$$
S(f)>>S_{n}(f),
$$

where $S(f)$ is the PSD of PEM fuel cell microfluctuation, and $S_{n}(f)$ is PSD of measuring equipment intrinsic noises.

Graph $S^{\prime \prime}(f)$ (Figure 4) shows that fluctuations have a steadily decreasing character which can be described by fractional power dependence in accordance with theoretical speculations (see Section 2.2):

$$
S^{\prime}(f) \sim \frac{1}{f^{\gamma}}
$$

Fractional factor increasing in the range of $10-100 \mathrm{~Hz}$ can be increased by the shunting action of doubleelectrical layer capacity, $C$.

\subsection{Single PEM fuel cell electrical fluctuation under different water management modes}

Water balance substantially defines efficiency and stability of the PEM fuel cell operation. Water balance 
control is generally carried out by variation of three parameters: $\mathrm{FC}$ temperature $T_{\mathrm{FC}}$, anode $T_{\mathrm{HA}}$, and $T_{\mathrm{HC}}$ cathode humidifiers temperature. For this reason, let us consider the influence of these parameters on FC electrical fluctuations arising during the FC operation.

FC temperature is one of the most important parameters defining the FC operation. Therefore, an analysis of influence on FC fluctuation is a task of the highest priority. The complexity of $\mathrm{FC}$ temperature characteristics investigation is caused by the fact that the fuel cell temperature directly defines water balance in the MEA.

Experimental results of the reduced PSD $S^{\prime}(f)$ measured at different $\mathrm{FC}$ temperatures are presented in Figure 5. The analysis of these results allows us to conclude that electrical fluctuation at higher frequencies range $(f>10 \mathrm{~Hz})$ demonstrates a slow decrease with the growth of a temperature, while low frequency fluctuations do not show a significant temperature dependence.

Dependence of the analysis of PEMFC fluctuation on anode humidifier temperature, $T_{\mathrm{HA}}$, (Figure 6) does not reveal any significant dependency. It can

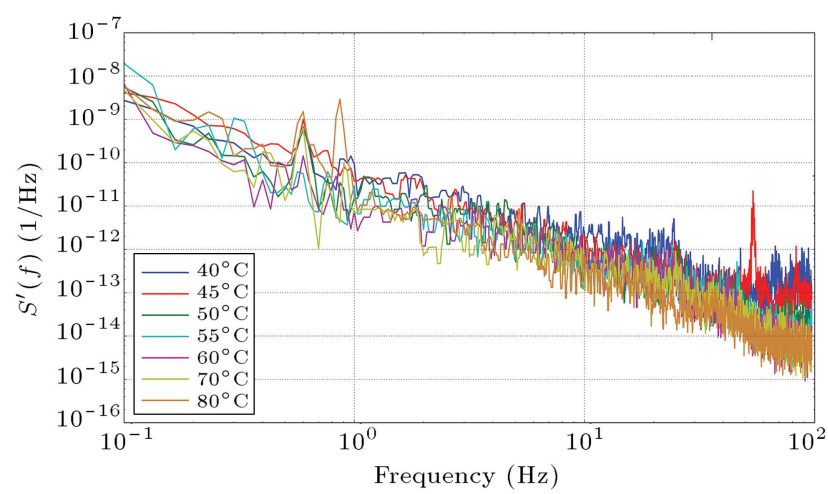

Figure 5. Reduced PSD $S^{\prime}(f)$ of PEM fuel cell electrical fluctuation measured at different values of $\mathrm{FC}$ temperature $T_{\mathrm{FC}}$.

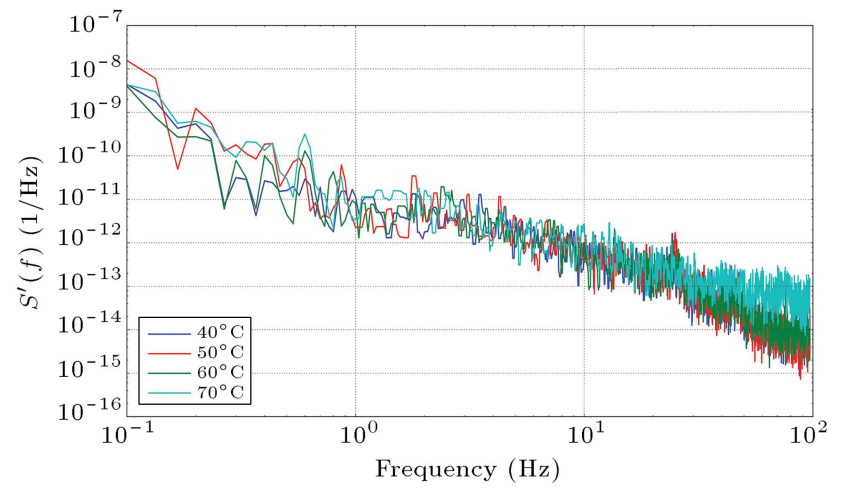

Figure 6. Reduced PSD $S^{\prime}(f)$ of PEM fuel cell electrical fluctuation measured at different values of anode humidifier temperature $T_{\mathrm{HA}}$. be explained by the fact that anode reactions are not usually a limiting factor for PEMFC operation of efficiency and stability.

Reduced PSD $S^{\prime}(f)$ of PEM fuel cell electrical fluctuation measured at different values of cathode humidifier temperature, $T_{\mathrm{HC}}$, is presented in Figure 7. This figure shows that FC temperature has substantial influence on fluctuation spectral characteristics. Fluctuations at all frequencies remain almost constant with increasing temperature up to $40^{\circ} \mathrm{C}\left(T_{\mathrm{HC}}<40^{\circ} \mathrm{C}\right)$ and abruptly increase more than one order to higher temperatures (Figure 7).

Dependence of the hydrogen fuel cell impedance characteristic on anode humidifier temperature is presented in Figure 8. One can see that FC impedance absolute values $\left|Z_{\mathrm{FC}}\right|$ at low frequency range $(f<$ $10 \mathrm{~Hz}$ ) have a character of dependence on temperature $T_{\mathrm{HC}}$ similar to the changing behavior of fluctuation characteristics kept at almost constant level in the temperature range of $T_{\mathrm{HC}}<40^{\circ} \mathrm{C}$ and abrupt increase in the range of $T_{\mathrm{HC}}>40^{\circ} \mathrm{C}$. Strong temperature dependence of impedance and fluctuation characteristics can be explained by active water condensation on the MEA and gas transport channel surfaces when the

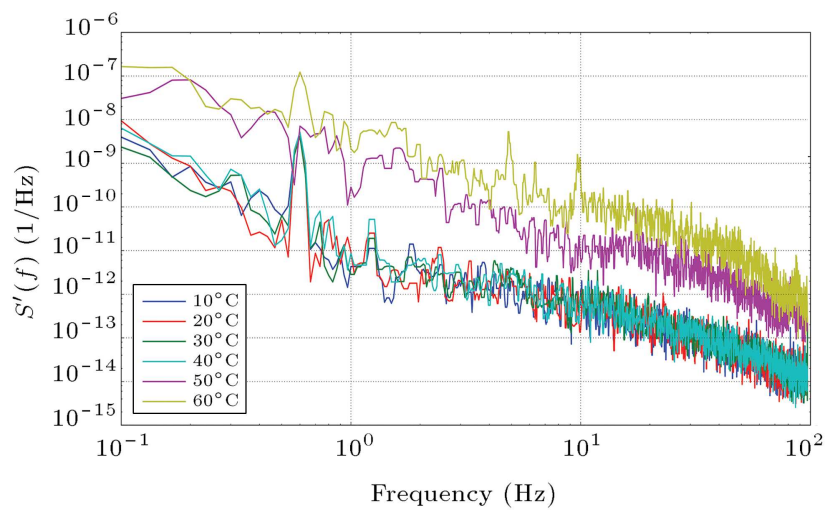

Figure 7. Reduced PSD $S^{\prime}(f)$ of PEM fuel cell electrical fluctuation measured at different values of cathode humidifier temperature $T_{\mathrm{HC}}$.

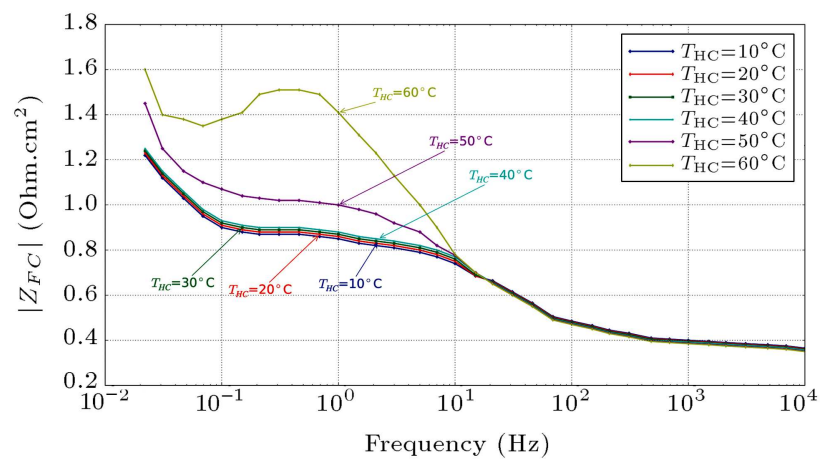

Figure 8. Dependence of FC impedance absolute values $\left|Z_{\mathrm{FC}}\right|$ on frequency $f$ at different cathode humidifier temperatures $T_{\mathrm{HC}}$. 
temperature of a PEM fuel cell $T_{\mathrm{FC}}$ becomes close to the dew point temperature of cathode gas. PEM fuel cell operation in this mode can lead to MEA active surface part blocking and non-uniformity of the current distribution along the membrane surface.

To check the above assumption that PEMFC fluctuation significantly depends on water management processes, the fluctuation characteristics have been studied in a flooding mode. The measurement of FC electrical fluctuation time dependence has been carried out (Figure 9) for a $\mathrm{FC}$ operating in the following operation mode: $T_{\mathrm{FC}}=60^{\circ} \mathrm{C} ; T_{\mathrm{HA}}=70^{\circ} \mathrm{C} ; T_{\mathrm{HC}}=$ $70^{\circ} \mathrm{C} ; Q_{A}=600 \mathrm{ml} / \mathrm{min} ; Q_{C}=600 \mathrm{ml} / \mathrm{min}$; and $P_{A}=P_{C}=300 \mathrm{kPa}$. Such an operation mode due to high anode and cathode humidifier temperature leads to water excess in the MEA of the fuel cell. Figure 9 shows that the fuel cell fluctuations for this mode are characterized by a large quantity of short sharp impulses which affect the PSD increasing in a middlefrequency range (Figure 10). By a decrease of anode

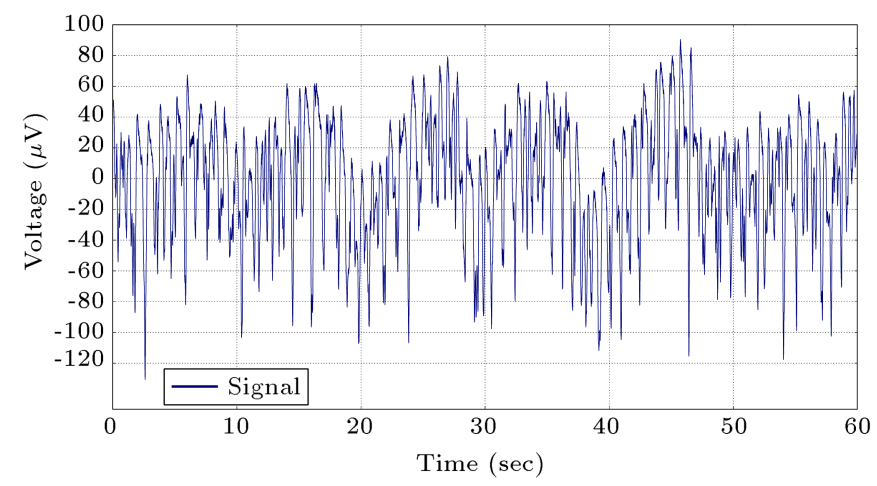

Figure 9. Electrical fluctuation time dependence for the PEM fuel cell operating at next operating mode: $T_{\mathrm{FC}}=60^{\circ} \mathrm{C} ; T_{\mathrm{HA}}=70^{\circ} \mathrm{C} ; T_{\mathrm{HC}}=70^{\circ} \mathrm{C} ; Q_{A}=600$ $\mathrm{ml} / \mathrm{min} ; Q_{C}=600 \mathrm{ml} / \mathrm{min} ; P_{A}=P_{C}=300 \mathrm{kPa}$.

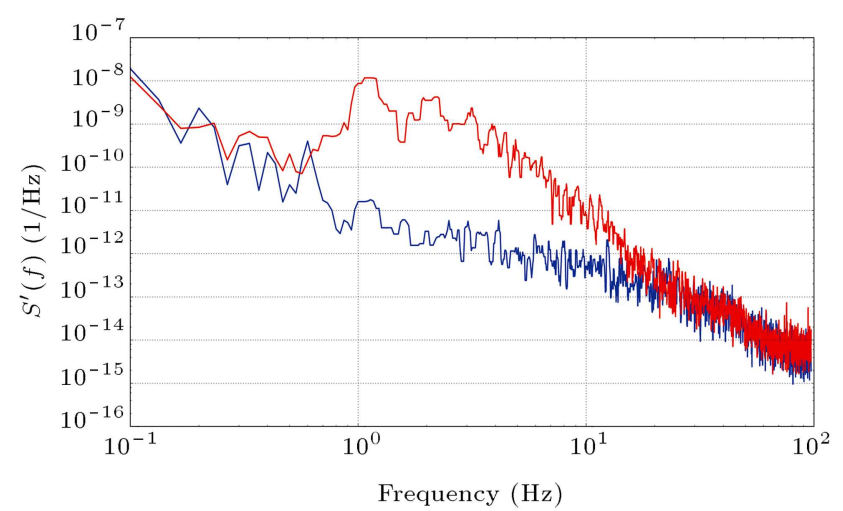

Figure 10. Electrical fluctuation PSD of the PEM fuel cell operating in operation mode: 1) $T_{\mathrm{FC}}=60^{\circ} \mathrm{C}$; $T_{\mathrm{HA}}=70^{\circ} \mathrm{C} ; T_{\mathrm{HC}}=70^{\circ} \mathrm{C} ; Q_{A}=600 \mathrm{ml} / \mathrm{min} ; Q_{C}=600$ $\left.\mathrm{ml} / \mathrm{min} ; P_{A}=P_{C}=300 \mathrm{kPa} ; 2\right) T_{\mathrm{FC}}=60^{\circ} \mathrm{C}$;

$T_{\mathrm{HA}}=50^{\circ} \mathrm{C} ; T_{\mathrm{HC}}=\operatorname{dry} ; Q_{A}=600 \mathrm{ml} / \mathrm{min} ; Q_{C}=600$ $\mathrm{ml} / \mathrm{min} ; P_{A}=P_{C}=300 \mathrm{kPa}$. and cathode humidifiers' temperatures, the PSD of fluctuations has returned to its original form.

\section{Results and discussion}

Analysis of experimental results presented in Section 3.3 showed that electrical fluctuation depends on physical processes inside the PEMFC, especially on water condensation and evaporation processes in the MEA. It allows one to reasonably suppose that using the information properties of electrical fluctuations allows for developing an effective tool for PEMFC diagnostics. However, due to low maximum potential of single cell (less than 1.2 V), a PEMFC stack is usually used for practical application. Here, the question of applicability of the described approach was raised to estimate technical state of the stacks.

\subsection{Experimental setup for PEMFC stack electrical fluctuation measurement}

The Electrical Noise Analysis (ENA) was applied to study the 8-cell hydrogen PEMFC (EPICEA v2) with the cell surface of $220 \mathrm{~cm}^{2}$ in Fuel Cell Laboratory (Belfort, France). The electrical parameters, such as voltage of stack and/or on each single stack cell, electrical current, impedance, etc., were measured in galvanostatic (0-170A) or potentiostatic (0-9V) modes. Electrical fluctuation measurement was performed by means of specific equipment based on NI-9239 of National Instrument Inc. The root mean square value of intrinsic noise of the equipment for fluctuation measurement is about $70 \mu \mathrm{V}$ that is sufficient to measure FC voltage fluctuations.

To develop methods for diagnosis and prognosis of the PEMFCs, the state of health information on the current technical state of a PEMFC is required. The information was provided by the set of additional sensors. Test benches were equipped with sensors for temperature, pressure, humidity, and flow rate of reactants. All sensors are direct descriptors, i.e., using direct recording of physical parameters. A simplified diagram of sensor placement is shown in Figure 11. The main setup parameters are presented in Table 2 .

Table 2. Technical characteristics of experiment for PEMFC stack electrical fluctuation analysis.

\begin{tabular}{cc}
\hline Characteristic & Value \\
\hline Nominal power & 600 Watts \\
Current & $0-170 \mathrm{~A}$ \\
Relative humidity & $50 \%$ \\
Temperature of FC & $75-80^{\circ} \mathrm{C}$ \\
Absolute pressure & $1.5 \mathrm{bar}$ \\
Reagents stoichiometry of anode/cathode & $1.5 / 2$ \\
\hline
\end{tabular}




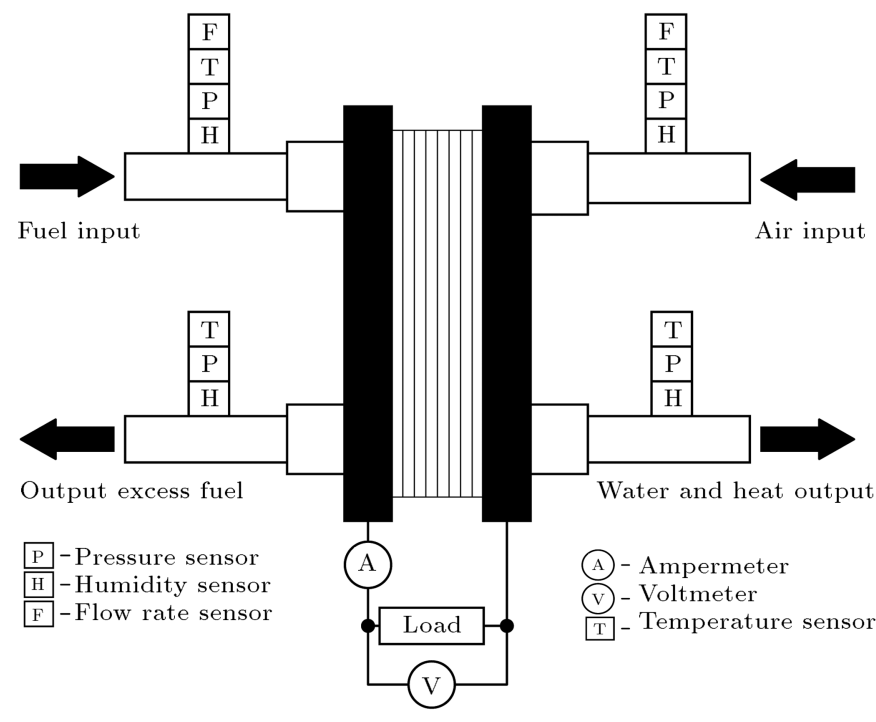

Figure 11. Acquisition of thermophysical parameters for generating direct descriptors.

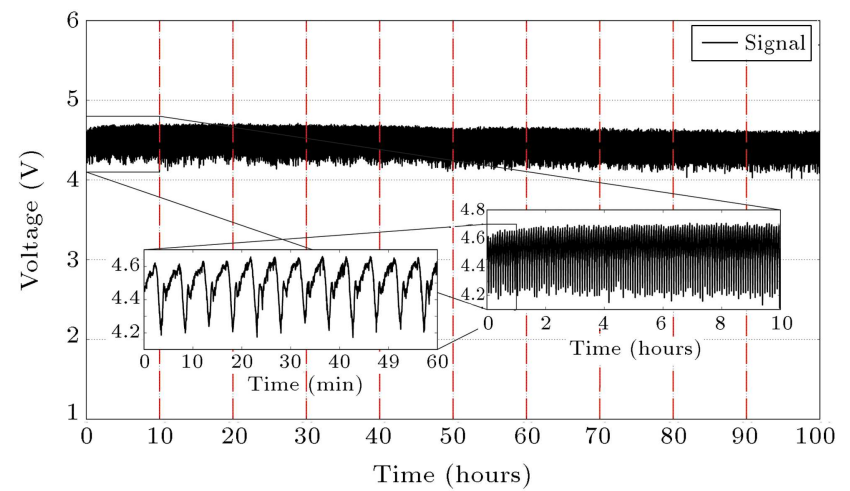

Figure 12. PEMFC voltage fluctuation in galvanostatic mode.

\subsection{PEMFC stack electrical fluctuations}

To realize an experimental study, a PEMFC was run galvanostatically for 100 hours with the current of $170 \mathrm{~A}\left(772 \mathrm{~mA} / \mathrm{cm}^{2}\right)$ with the other parameter listed in Table 2. Typical voltage fluctuations for 170A galvanostatic mode are presented in Figure 12. There are clearly-expressed quasi-periodic oscillations with the characteristic time of about 5 minutes. Within the structure of electrical fluctuations, there are also a lot of small stochastic signals distributed within wide ranges of frequencies and amplitudes.

Before applying ENA, the Direct Current (DC) and low frequency components have been removed using 5-order digital Butterworth high-pass filter with the cut-off frequency of $0.1 \mathrm{~Hz}$. The frequency range has been chosen in accordance with the results obtained in Section 3.3 for a single PEMFC. To obtain spectral characteristics of electrical fluctuations, PSD has been calculated on the basis of Fast Fourier Transform (FFT).
PSDs of electrical fluctuations measured every 10 hours for a PEMFC run for 100 hours with the load current of $170 \mathrm{~A}$ are presented in Figure 13. As one can see, PSD has a complex structure within the range of $100 \mathrm{mHz}$ to $10 \mathrm{~Hz}$. And, in particular, it is established that in a low frequency range, the fluctuation has the flicker-noise nature that coincides with the results obtained for a single PEMFC in Section 3.3. This experimental result also confirms the theoretical assumptions stated in Section 2.2. Distortion of fluctuations spectrum in higher frequency range can be explained by PEMFC control equipment operation. It is shown that since flicker-noise component of electrical fluctuation comprises diagnostic features reflecting technical state of a PEMFC, we will further focus on the corresponding frequency range lower than $1 \mathrm{~Hz}$.

Figure 14 shows the evolution of fluctuation parameters estimated as values of PSD on specific frequencies. At the initial stage, all parameters that can be explained by operating process stabilization decrease. After 30 hours, all parameters have the increasing trend that can be caused by decreasing effective surface due to water accumulation within the MEA or by degradation of catalyst.

Due to the flicker-noise nature of PEMFC electrical fluctuations, it is interesting to analyze the possibil-

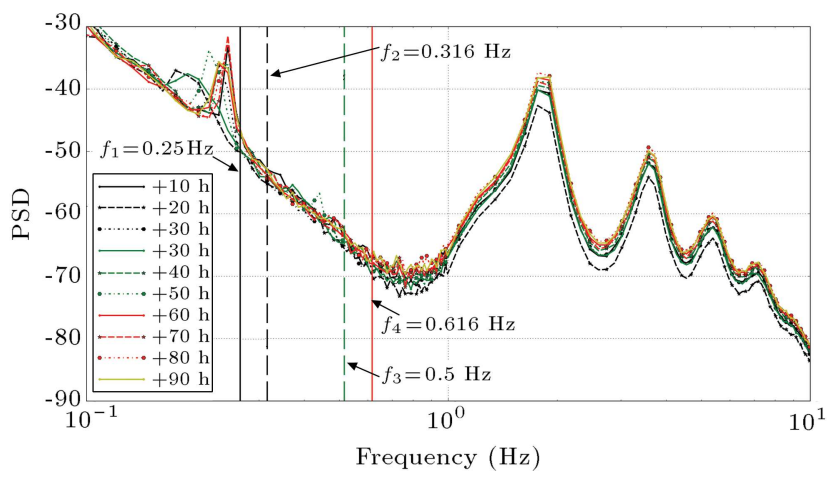

Figure 13. Power spectrum density of PEMFC stack voltage fluctuation.

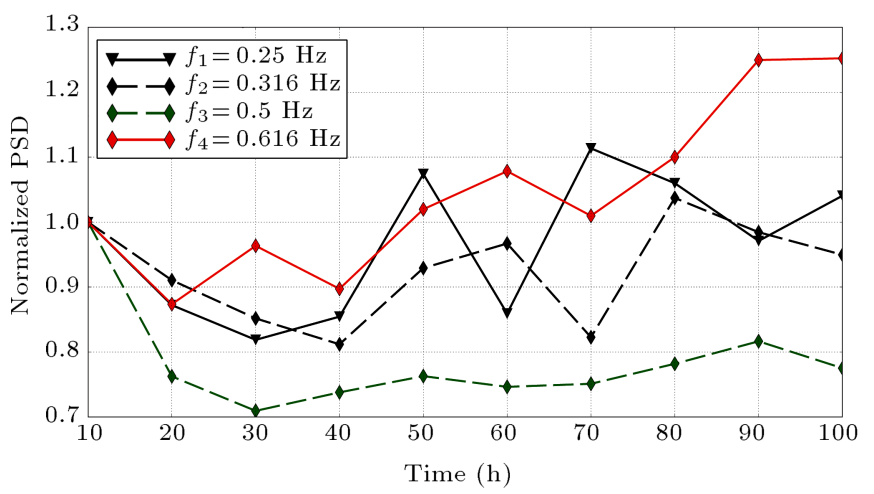

Figure 14. Evolution of the fluctuation parameters of PEMFC stack during 100 hours. 


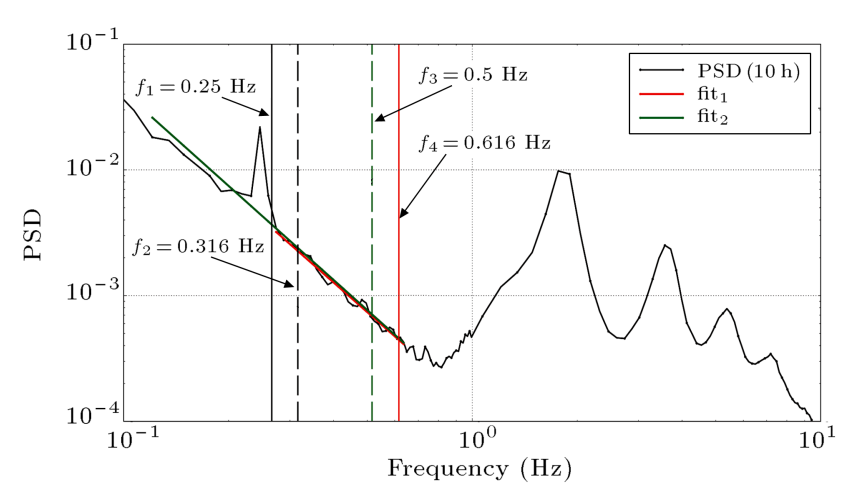

Figure 15. PSD of the first 10 hours with approximations.

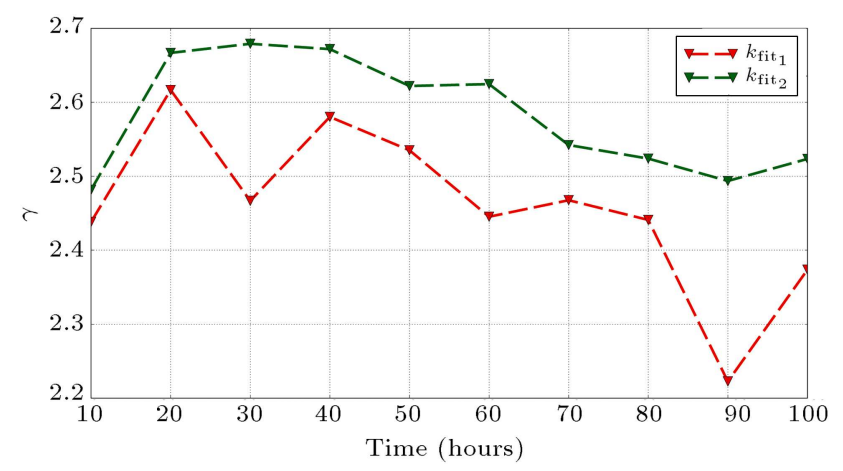

Figure 16. Evolution of the parameters of a flicker noise component over time.

ity of using the flicker-noise parameter $\gamma$ (see Eq. (12)) to diagnose its technical state. This parameter is calculated as a result of fitting the PSD in doublelogarithmic scale by the straight line. This fitting has been performed in two frequency ranges (see Figure 15) of $0.25 \mathrm{~Hz}$ to $0.65 \mathrm{~Hz}$ (range 1) and of $0.13 \mathrm{~Hz}$ to $0.65 \mathrm{~Hz}$ (range 2).

As seen in Figure 16, the parameter $\gamma$ corresponding to the frequency range 2 (Figure $16, k_{\text {fit } 2}$ ) demonstrates a more stable trend and is more preferable to diagnostic procedures. This fact has strong physical interpretation: Wider frequency range has greater informative value. It should also be noted that the behaviors of parameter $\gamma$ and PSD parameters at specific frequencies substantially coincide. At initial stages after setting new operation parameters ( $I=$ $170 \mathrm{~A}$ ), the parameter $\gamma$ increases until stable operation condition is achieved. Value of $\gamma$ after stabilization is equal to 2.67 that corresponds to $\Delta \psi=0.167$. It means that condensation process slightly predominates over evaporation. After that, the parameter slowly decreases over time. So long as PEMFC stack works under high current density $\left(j=0.77 \mathrm{~A} / \mathrm{cm}^{2}\right)$, heating of membrane intensifies evaporation that leads to decreasing water content within MEA that is evidenced by the parameter $\gamma$ decreasing. This conclusion is confirmed by the fact that the voltage of PEMFC stack also decreases. Here, we notice that both approaches can be used to organize diagnostics of the PEMFC. Parameter $\gamma$ is more preferable since it is more stable, but it requires more computational resources for calculation.

\section{Conclusions}

The possibilities of spectral characteristics of electrical fluctuations of the PEMFC to perform diagnostic procedures for the PEMFC were observed. It has been theoretically shown that water management processes in the MEA involve electrical fluctuations with flickernoise spectrum. This conclusion is confirmed by the experimental results which show a clear flicker-noise component in low frequency range (less than $10 \mathrm{~Hz}$ for a single PEMFC and less than $1 \mathrm{~Hz}$ for a PEMFC stack). It has been established that the PEMFC electrical fluctuation characteristic depends on water management processes in the cell. Therefore, analysis of the electric fluctuation provides an opportunity to predict drying or flooding of the membrane electrodes assembly which could lead to a dramatic decrease in the produced power.

On the basis of the experimental data, the frequency range $(0.1-1 \mathrm{~Hz})$ convenient as for single cell and as for stack diagnostic purposes was reduced. Analysis of experimental results allows for making the conclusion that the two types of diagnostic features estimated using PSD (flicker-noise parameter $\gamma$ and PSD values at specific frequencies) sensitive to degradation processes inside the PEMFC can be found. It has been shown that parameter $\gamma$ is more convenient for diagnostics application; however, parameters of other types are easier to measure.

The preliminary results indicate that noise measurement can be an effective tool for the fuel cell diagnosis, and the obtained results can be used to evaluate the degree of degradation of the object that would allow the control of remaining useful life by changing the FC settings. Thereby, fluctuation diagnosis can allow us to take a new step in the development of diagnostics and prognostics of electrochemical power sources.

\section{Acknowledgements}

This work has been supported by the ANR project PROPICE (ANR-12-PRGE-0001) funded by the French National Research Agency.

\section{References}

1. Barbir, F., PEM Fuel Cells - Theory and Practice, Academic Press (2012).

2. Chen, M., Andreasen, S.J., Rosendahl, L., Kær, S.K. and Condra, T. "System modeling and validation of 
a thermoelectric fluidic power source: Proton exchange membrane fuel cell and thermoelectric generator (PEMFC-TEG)", Journal of Electronic Materials, 39(9), pp. 1593-1600 (2010). DOI:10.1007/s11664-0101270-9

3. Jouin, M., Gouriveau, R., Hissel, D., Pera, M.C. and Zerhouni, N. "Prognostics and health management of PEMFC - state of the art and remaining challenges", International Journal of Hydrogen Energy, 38, pp. 15307-15317 (2013). DOI:10.1016/j.ijhydene.2013.09.051

4. Petrone, R., Zheng, Z., Hissel, D., Pera, M., Pianese, C., Sorrentino, M., Becherif, M. and YousfiSteiner, N. "A review on model-based diagnostics methodologies for PEMFCs", International Journal of Hydrogen Energy, 38, pp. 7077-7091 (2013). DOI:10.1016/j.ijhydene.2013.03.106.

5. Zheng, Z., Petrone, R., Péra, M.-C., Hissel, D., Becherif, M., Pianese, C., Steiner, N.Y. and Sorrentino, M. "A review on non-model based diagnostics methodologies for PEM fuel cell stacks and systems", International Journal of Hydrogen Energy, 38(21), pp. 8914-8926 (2013). DOI:10.1016/j.ijhydene.2013.04.007

6. Wang, R., Zhan, Y. and Zhou, H. "Application of transform in fault diagnostics of power electronics circuits", Scientia Iranica, 19(3), pp. 721-726 (2012). DOI:10.1016/j.scient.2011.06.013

7. Evdokimov, Yu.K., Denisov, E. and Martemianov, S. "Hydrogen fuel cell electrical noise and study of its diagnostics properties", Nonlinear World, 7(9), pp. 706-713 (2009).

8. Martemianov, S., Adiutantov, N., Evdokimov, Y.K., Madier, L., Maillard, F. and Thomas, A. "New methodology of electrochemical noise analysis and applications for commercial li-ion batteries", Journal of Solid State Electrochemistry, 19(4), pp. 1-8 (2015). DOI:10.1007/s10008-015-2855-2

9. Evdokimov, Yu. and Denisov, E. "Fluctuation-noise diagnostics of optical system power supply units based on fuel cell", Proc. SPIE 8787, pp. 87870E-87870E-11 (2013). DOI:10.1117/12.2020894

10. Claycomb, J.R., Brazdeikis, A., Miller, J.H., et al. "Nondestructive testing of PEM fuel cells", IEEE Transactions on Applied Superconductivity, 13(2), pp. 211-214 (2003). DOI:10.1109/TASC.2003.813687

11. Zhang, F.Y., Yang, X.G. and Wang, C.Y. "Liquid water removal from a polymer electrolyte fuel cell", Journal of The Electrochemical Society, 153(2), pp. A225-A232 (2006). DOI:10.1149/1.2138675

12. Fang, S.-Y., Teoh, L.G., Huang, R.-H., Chao, W.-K., Lin, T.-J., Yang, K.-C., Hsueh, K.-L. and Shieu, F.S. "Effect of adding zinc oxide particles to the anode catalyst layer on the performance of a proton exchange membrane fuel cell", Journal of Electronic Materials, 43(9), pp. 3601-3610 (2014). DOI:10.1007/s11664-014$3246-7$

13. Katzel, J., Markotter, H., Arlt, T., Klages, M., Haussmann, J., Messerschmidt, M., Kardjilov, N., Scholta, J., Banhart, J. and Manke, I. "Effect of ageing of gas diffusion layers on the water distribution in flow field channels of polymer electrolyte membrane fuel cells", Journal of Power Source, 301, pp. 386-391 (2016). DOI:10.1016/j.jpowsour.2015.10.004

14. Khazaee, I., Ghazikhani, M. and Mohammadiun, M. "Experimental and thermodynamic investigation of a triangular channel geometry PEM fuel cell at different operating conditions", Scientia Iranica, 19(3), pp. 585593 (2012). DOI:10.1016/j.scient.2011.11.039

15. Liu, X., Guo, H. and Ma, C. "Water flooding and two-phase flow in cathode channels of proton exchange membrane fuel cells", Journal of Power Sources, 156, pp. $267-280$ (2006).

DOI:10.1016/j.jpowsour.2005.06.027

16. Song, M., Pei, P., Zha, H. and Xu, H. "Water management of proton exchange membrane fuel cell based on control of hydrogen pressure drop", Journal of Power Sources, 267, pp. 655-663 (2014). DOI:10.1016/j.jpowsour.2014.05.094

17. Thomas, A., Maranzana, G., Didierjean, S., Dillet, J. and Lottin, O. "Thermal and water transfer in PEMFCs: Investigating the role of the microporous layer", International Journal of Hydrogen Energy, 39, pp. 2649-2658 (2014). DOI:10.1016/j.ijhydene.2013.11.105

18. Zaffou, R., Yi, J.S., Kunz, H.R. and Fenton, J.M. "Temperature-driven water transport through membrane electrode assembly of proton exchange membrane fuel cells", Electrochemical and Solid-State Letters, 9(9), pp. 418-422 (2006). DOI:10.1149/1.2218306

19. Zhan, Z., Wang, C., Fu, W. and Pan, M. "Visualization of water transport in a transparent PEMFC", International Journal of Hydrogen Energy, 37, pp. 1094-1105 (2012). DOI: 10.1016/j.ijhydene.2011.02.081

20. Erdelyi, A., Tables of Integral Transforms, 1, McGrawHill Inc. (1954).

\section{Biographies}

Evgenii Denisov is an Associate Professor of Department of Radio-Electronic and Information \& Measuring Technology of Kazan National Research Technical University named after A.N. Tupolev-KAI (KNRTU-KAI). He received his $\mathrm{PhD}$ degrees in 2011 from University of Poitiers, France, and in 2012 from KNRTU-KAI. His research interests focus on technical diagnostics of electrochemical systems, hydrogen energetics, and digital signal processing.

Yury K. Evdokimov is a Full Professor, Head of Department of Radio-Electronic and Information \& 
Measuring Technology (RIIT) in Kazan National Research Technical University named after A.N. TupolevKAI (KNRTU-KAI). His main research interest is inverse operator problem and its applications in measuring technique, acoustics, and electrochemistry; fractal geometry and fractional operators for analysis and synthesis complex system; automation of measurement, control, and diagnosis; sensors.

Raoul Rashid Nigmatullin was born in Kazan, Tatarstan Republic, Russian Federation in 1947 year. He finished Kazan State University with honors in 1970 year. He defended his PhD thesis successfully in 1974 year, then his Doctorate thesis in 1992 year. As of 1997, he has become a Full Professor of the Theoretical Physics Department in Kazan State University. Before 2015, he has worked in Kazan Federal University. Since 2015, he has been working in Kazan National Research Technical University (KNRTU-KAI) in Radioelectronic and Informative-Measurements Technics Department. His scope of scientific interests is rather high and includes the fractal geometry, fractional calculus, dielectric spectroscopy, and development of new statistical methods for treatment of different random sequences. He is the author of more than 200 publications, and as the leading Russian scientist, he has more than 2000 citations.

Serguei Martemianov is a Full Professor of Chemical \& Energy Engineering in University of Poitiers, France.
He received his $\mathrm{PhD}$ degree in 1976 from Moscow State University, Russia. Afterwards, he has worked in Frumkin Institute of Electrochemistry (Moscow), INP de Grenoble (France) and in University of Poitiers since 1996. He is the author of monograph "Turbulent Diffusion Layer in Electrochemical Systems" and more than 100 articles in international journals. His research interests include turbulent mass transfer, transfer processes in electrochemical systems, electrochemical energetics (fuel cells, batteries), modeling of near interface transfer processes, and development of new instrumentation methods.

Anthony Thomas is an Associate Professor of Mechanical \& Energy Engineering in University of Poitiers, France. He received his PhD degree in 2012 from University of Lorraine, France. His research interests include charge transfer, heat transfer, and mass transport into electrochemical systems, as PEM Fuel Cell \& Electrolyser and Battery and associated metrology development.

Nikolai Adiutantov received his Diploma of Specialist in Information Security from Kazan Federal University, Kazan in 2012. He is currently pursuing his joint PhD degree in University of Poitiers, France and at Kazan National Research Technical University named after A.N. Tupolev-KAI (KNRTU-KAI). His primary research interest is focused on technical diagnosis of fuel cells, Li-ion batteries, etc. 